\title{
Fertilization following mixed insemination with 'cervix-selected' and 'unselected' spermatozoa in the rabbit
}

\author{
B. Fischer* and C. E. Adams \\ A.R.C. Institute of Animal Physiology, Animal Research Station, 307 Huntingdon Road, \\ Cambridge CB3 OJQ, U.K.
}

\begin{abstract}
Summary. The possible selection of spermatozoa for fertilization by the female genital tract was investigated using genetically homogeneous, numerically adjusted 'cervix-selected' and 'unselected' rabbit spermatozoa. Samples of spermatozoa were marked by $15 \mathrm{~min}$ exposure to $1.3 \mathrm{mg}$ TEPA $/ \mathrm{ml}$ and then washed for $15 \mathrm{~min}$. TEPA-treated and control samples were inseminated alternately into the vagina (= 'cervix-selected') or uterine horns (= 'unselected') of prospective donors. After $6 \mathrm{~h}$ spermatozoa were recovered from the uterine horns of the donors. Equal numbers of 'selected' and 'unselected' spermatozoa were inseminated either into the uterine horns ( 24 does) or oviducts ( 25 does) of recipients. The fertilization rates were 48 and $72 \%$, respectively. Significantly more eggs were fertilized by untreated than by TEPAtreated spermatozoa. Almost identical fertilization rates, however, were observed between 'cervix-selected' and 'unselected' spermatozoa. It is concluded, therefore, that in the rabbit no selection of (preincubated) spermatozoa for fertilization takes place at the cervical level.
\end{abstract}

\section{Introduction}

On the assumption that a high proportion of ejaculated spermatozoa are defective, Cohen \& McNaughton (1974) investigated a possible selection of spermatozoa for fertilization by the female genital tract in rabbits. They found that spermatozoa recovered from upper parts of the female tract were more potent to fertilize than were ejaculated spermatozoa. For example, whereas $1.6 \times 10^{4}$ 'tubal' or $7 \times 10^{3}$ 'uterine' spermatozoa were required to produce one young, $1.9 \times 10^{7}$ ejaculated spermatozoa were necessary. It was therefore concluded that part of the function of the female genital tract is the selection of spermatozoa for fertilization.

The mechanisms whereby the genital tract recognizes 'fitter' spermatozoa are obscure. There is evidence for a lack of recognition of grossly defective or abnormal spermatozoa; for example, in the rabbit, spermatozoa damaged by X-irradiation (Amoroso \& Parkes, 1947; Overstreet \& Adams, 1971; Bedford \& Overstreet, 1972; Götze, 1973) or by treatment with TEPA (Beil, Bauman \& Graves, 1976) are able to move through the female tract and fertilize, although the resulting zygotes do not develop beyond the first cleavage stages. Diploid rabbit spermatozoa may also reach the site of fertilization (Mortimer, 1977). Chang, Marston \& Hunt (1964) and C. E. Adams (unpublished) found that spermatozoa from the snowshoe hare (Lepus americanus) or brown hare (Lepus europaeus), when mixed with rabbit spermatozoa and inseminated into rabbit does, could compete effectively in fertilization. The number of spermatozoa necessary for

* Present address: Abteilung Anatomie und Reproduktionsbiologie der RWTH, Medizinisch-Theoretische Institute, Melatener Strasse 211, D-5100 Aachen, West-Germany. 
selection is also puzzling. Chang (1951), for example, found that, irrespective of whether $200 \times$ $10^{6}$ or $20 \times 10^{6}$ spermatozoa had been deposited into the vagina, the numbers in the oviducts were relatively constant.

Cohen \& McNaughton (1974) used genetically marked spermatozoa to identify offspring at term. However, Overstreet \& Adams (1971) showed that spermatozoa from different bucks, even from the same breed, may not compete equally. In their experiments spermatozoa from some bucks were always superior in their ability to fertilize in comparison with those from others. Nevertheless, the results of an experiment in which genetically homogeneous spermatozoa were used (Overstreet \& Katz, 1977) lend support to the alleged selection of spermatozoa. Overstreet \& Katz (1977) found that spermatozoa which had passed through the genital tract of female rabbits after vaginal insemination showed a distinct advantage over spermatozoa that were tubally inseminated. The spermatozoa were recovered from the oviducts $16 \mathrm{~h}$ after vaginal or tubal insemination and re-inseminated into the oviducts of recipients shortly after ovulation. One group of spermatozoa had been previously chemically marked with FITC (Overstreet \& Bedford, 1974) or X-irradiated. Although considerably fewer in number (the ratio between 'selected' and 'unselected' spermatozoa ranged from 1:3.5 to 1:200) the 'selected' spermatozoa fertilized as many eggs as did the 'unselected' ones.

In the studies referred to above the conditions experienced by the competing sperm populations varied in respect to the length of exposure in the female tract, to capacitation time and/or milieu. The number of spermatozoa and insemination volumes also varied. We have therefore attempted to re-evaluate the question of selection of spermatozoa by the female tract, using a system of competitive fertilization between 'selected' and 'unselected' spermatozoa in which very similar experimental conditions existed for the competing populations of spermatozoa. For this purpose a chemical marker was used to identify the fertilizing spermatozoon. Beil et al. (1976) had shown that treatment of rabbit spermatozoa with TEPA arrested cleavage at the 2-or 3-cell stage and that a mixed insemination of equal numbers of treated and untreated spermatozoa resulted in no statistically significant difference in the proportions of fertilized eggs. The use of TEPA necessarily involved the investigation of the eggs shortly after fertilization, but this period is more directly related to the postulated selection of spermatozoa than is the time of birth.

\section{Materials and Methods}

A total of 96 sexually mature female rabbits, 6 bucks of proven fertility, and 6 vasectomized bucks, all from our own colony, was used. Semen was collected with an artificial vagina (Adams, 1962) from 6 males, scored for motility, and pooled. The experimental design is shown in Text-fig. 1. One portion of the semen was mixed with saline-based medium (Dott, Harrison \& Foster, 1979); 1 part of semen to 2 parts of medium. Another portion of the semen was similarly diluted, but with medium which contained $2 \mathrm{mg}$ TEPA (TRIS(1-aziridinyl)phosphine oxide) $/ \mathrm{ml}$. After $15 \mathrm{~min}$ both samples were washed in $7.5 \mathrm{ml}$ sucrose-based medium containing serum albumin (Dott et al., 1979) for $15 \mathrm{~min}$ at $900 \mathrm{~g}$, reduced in volume, and inseminated into the vagina (= 'cervix-selected') or uterine horns (= 'unselected') of donors. The vaginally inseminated donors were mated with a vasectomized buck immediately after insemination. Better recoveries were obtained when the vaginal inseminate was of high density, small volume, and high motility. The TEPA-treated spermatozoa were inseminated alternately into the vagina or uterus. The average ( \pm s.e.m.) numbers inseminated ('unstained' spermatozoa based on nigrosin-eosin staining) were $264 \pm 14 \times 10^{6}$ into the vagina and $12.8 \pm 1.22 \times 10^{6}$ per uterine horn. The number of spermatozoa deposited into the vagina was at least 10 times higher than that deposited into the uterine horns but never unphysiologically high. No differences were observed betweeen TEPA-treated and untreated spermatozoa in motility, agglutination, or proportion stained. 


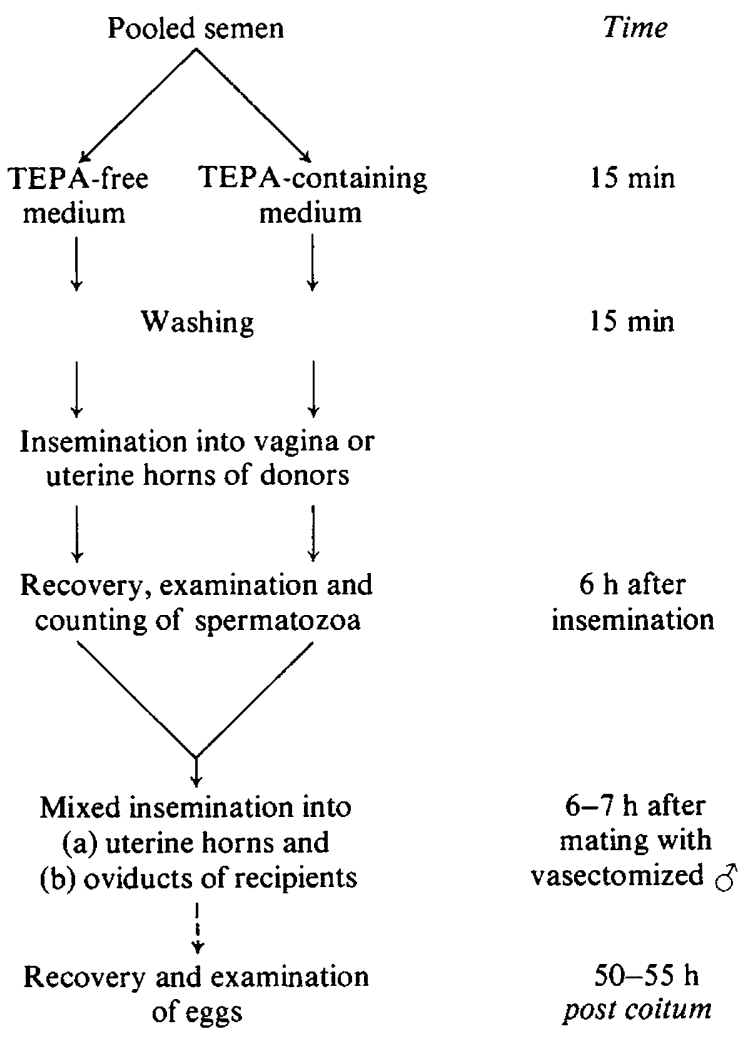

Text-fig. 1. The experimental schedule for assessment of fertilizing ability of 'cervix-selected' and 'unselected' rabbit spermatozoa.

The does were killed by a rapid intravenous injection of pentobarbitone sodium, $200 \mathrm{mg} / \mathrm{ml}$ (Expiral; Abbott Laboratories Ltd, Queenborough, Kent), $6 \mathrm{~h}$ after insemination and were bled out for 2-3 min before excision of the genital tract. Spermatozoa were recovered from the uterine horns by flushing each horn with $5 \mathrm{ml}$ sucrose-based medium. The cervices were removed beforehand and not flushed. The motility of recovered spermatozoa in the flushing medium often remained high for several hours. Equal numbers of 'cervix-selected' and 'unselected' spermatozoa from samples showing good motility were inseminated into the uterine horns or oviducts of 49 recipients approximately 6-7 h after mating with vasectomized bucks and the injection of 50 i.u. hCG (Gonadotrophon LH: Paines \& Byrne Ltd, Greenford, Middlesex). Inseminations were performed at laparotomy through a mid-line incision under pentobarbitone sodium, $60 \mathrm{mg} / \mathrm{ml}$ (Nembutal: Abbott; or Sagatal: May \& Baker Ltd, Dagenham, Essex) given i.v., and halothane (Fluothane: ICI Ltd, Macclesfield, Cheshire) delivered in nitrous oxide via a face mask. The number of spermatozoa was adjusted according to the rate of recovery. The mean ( \pm s.e.m.) numbers of spermatozoa inseminated were $98000 \pm 13000$ into the uterus and $20000 \pm 1300$ into the oviducts; the inseminate volumes were $0.34 \pm 0.03 \mathrm{ml}$ and $56 \pm 3.4 \mu$, respectively.

The recipients were autopsied $50-55 \mathrm{~h}$ post coitum, when eggs were recovered by flushing the oviducts with $2 \mathrm{ml} 0.9 \%(\mathrm{w} / \mathrm{v}) \mathrm{NaCl}$ solution. After an initial examination to determine the number of blastomeres, the eggs were fixed in a mixture of glacial acetic acid and absolute alcohol in a proportion of $1: 3(\mathrm{v} / \mathrm{v})$ and stained with lacmoid (Chang, 1952). The eggs were then examined microscopically to determine the appearance of the nuclei. 
The fertilization rates for the 'cervix-selected' and 'unselected' and TEPA-treated and untreated spermatozoa were compared by $\chi^{2}$ tests.

\section{Results}

Thirteen series of mixed inseminations of 'cervix-selected' and 'unselected' spermatozoa, involving a total of 49 recipients, were accomplished; 6 attempts were abandoned because too few spermatozoa were recovered from one of the donors.

The results are presented in Table 1 . Of the 24 does inseminated into the uterus, 2 failed to ovulate and in a further 6 cases fertilization failed; 4 of the tubally inseminated does failed to ovulate but the remaining 21 all contained some fertilized eggs. The total numbers of 'selected' and 'unselected' spermatozoa inseminated into the uteri were very similar amounting to 796590 and 775000 respectively, and into the oviducts 212556 and 213155 respectively. Of the eggs recovered from does with fertilization, the proportions fertilized were greater after tubal insemination (Table 1).

Table 1. Fertilization in rabbits re-inseminated with a mixture of TEPA-treated and untreated, 'cervixselected' or 'unselected' spermatozoa, recovered $6 \mathrm{~h}$ after insemination (percentages in parentheses)

\begin{tabular}{|c|c|c|c|c|c|c|c|c|c|c|}
\hline \multirow{3}{*}{$\begin{array}{l}\text { Site of } \\
\text { re-insemination }\end{array}$} & \multirow{2}{*}{\multicolumn{2}{|c|}{ No. of does }} & \multirow{3}{*}{$\begin{array}{l}\text { No. of } \\
\text { does } \\
\text { with } \\
\text { fertilized } \\
\text { eggs }\end{array}$} & \multicolumn{2}{|c|}{$\begin{array}{l}\text { No. of does inseminated with } \\
\text { TEPA-treated }\end{array}$} & \multirow{2}{*}{\multicolumn{2}{|c|}{ No. of eggs }} & \multicolumn{3}{|c|}{ No. of eggs with } \\
\hline & & & & \multirow{2}{*}{$\begin{array}{l}\text { 'Selected' } \\
\text { spermatozoa }\end{array}$} & \multirow{2}{*}{$\begin{array}{l}\text { 'Unselected' } \\
\text { spermatozoa }\end{array}$} & & & Normal & Arrested & Doubtful \\
\hline & Inseminated & Ovulating & & & & Recovered & Fertilized & cleavage & cleavage & cleavage \\
\hline \multirow{3}{*}{$\begin{array}{l}\text { Uteri } \\
\text { Oviducts }\end{array}$} & 24 & 22 & $16(73)$ & 8 & 8 & $114 t$ & $55(48)$ & $* 40(24)$ & $13(24)$ & $2(4)$ \\
\hline & 25 & 21 & $21(100)$ & 11 & 10 & 158 & $114(72)$ & *69 (61) & $39(34)$ & $6(5)$ \\
\hline & 49 & 43 & 37 & 19 & 18 & & & $* 109(64)$ & $52(31)$ & $8(5)$ \\
\hline
\end{tabular}

† Excluding does in which fertilization failed completely.

Values significantly different from the no. of eggs with arrested cleavage: ${ }^{*} P<0.01 ;{ }^{* * P} P<0.001$.

In most cases a clear distinction could be drawn between eggs undergoing normal development and those showing arrested cleavage (Plate 1). Arrested eggs had large, faint nuclei, often two occurring side by side in one blastomere (Plate 1), without nucleoli or clear nuclear membranes. Of the eggs examined, $7 \cdot 3 \%(8 / 109)$ could not be classified with certainty because fragmentation could not be excluded; these eggs are referred to as 'doubtful'. The proportion of eggs fertilized by TEPA-treated spermatozoa was significantly lower than that fertilized by untreated spermatozoa (Table 1).

The proportions of eggs fertilized by 'cervix-selected' and 'unselected' spermatozoa following uterine insemination and tubal insemination were not statistically significantly different (Table 2 ).

Table 2. Proportion of eggs fertilized by 'cervix-selected' and 'unselected' rabbit spermatozoa (percentages in parentheses)

\begin{tabular}{|c|c|c|c|}
\hline \multirow[b]{2}{*}{$\begin{array}{c}\text { Site of } \\
\text { re-insemination }\end{array}$} & \multirow[b]{2}{*}{$\begin{array}{l}\text { No. of eggs } \\
\text { fertilized }\end{array}$} & \multicolumn{2}{|c|}{ No. of eggs fertilized by } \\
\hline & & $\begin{array}{l}\text { 'Cervix-selected' } \\
\text { spermatozoa }\end{array}$ & $\begin{array}{l}\text { 'Unselected' } \\
\text { spermatozoa }\end{array}$ \\
\hline Uterine horns & 53 & $27 *(51)$ & $26(49)$ \\
\hline Oviducts & 108 & $56 *(52)$ & $52(48)$ \\
\hline Total & 161 & $83 *(52)$ & $78(48)$ \\
\hline
\end{tabular}

- Not significantly different from the number of eggs fertilized by 'unselected' spermatozoa $(P>0.05)$. 


\section{PLATE 1}
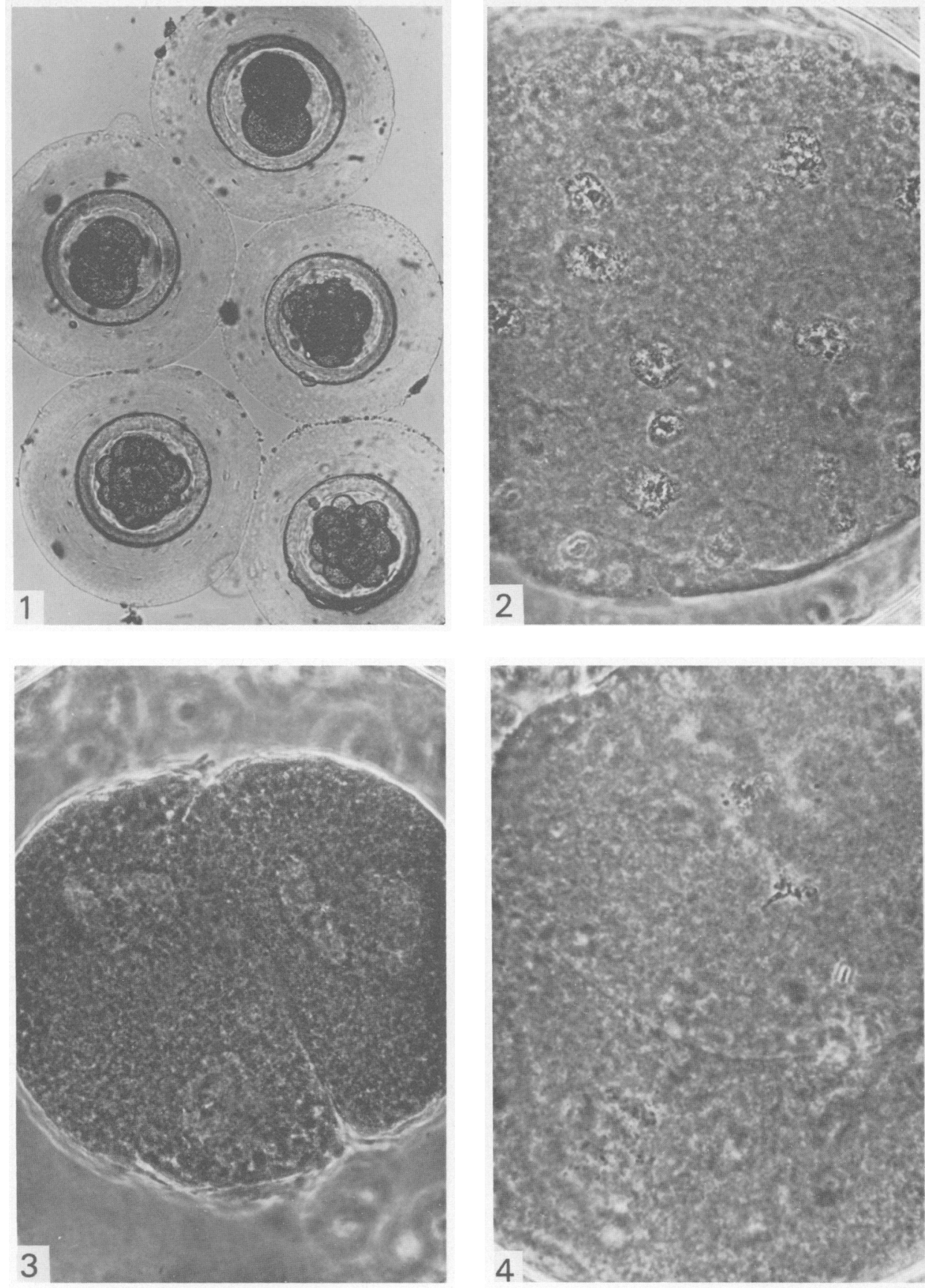

Fig. 1. Rabbit eggs recovered $55 \mathrm{~h}$ after insemination: the 2-cell eggs showing arrested cleavage are presumed to have been fertilized by TEPA-treated spermatozoa and the other 3 by untreated spermatozoa. $\times 160$.

Fig. 2. A rabbit egg fertilized by an untreated spermatozoon. Note the numerous normal nuclei. $\times 800$.

Fig. 3. A rabbit egg fertilized by a spermatozoon treated with TEPA. Note the enlarged nuclei which are duplicated. $\times 800$.

Fig. 4. A rabbit egg fertilized by a spermatozoon treated with TEPA. Note condensed chromatin. which is dispersed, and loss of nuclear membranes. $\times 800$. 


\section{Discussion}

The present results provide no evidence for a superiority of 'cervix-selected' over 'unselected' (uterine inseminated) spermatozoa when competing in fertilization, whether inseminated into the uterus or the oviducts (Table 2), and they do not support Cohen \& McNaughton's (1974) postulate that 'defective' spermatozoa are selected against at least at the cervical level. The results of Cohen \& McNaughton (1974) could have been due to differences in the fertilizing ability of spermatozoa from bucks belonging to the same or to different breeds (Beatty, 1960; Overstreet \& Adams, 1971), in the time for and after capacitation (Roche, Dziuk \& Lodge, 1968), in motility (Dandekar, Vaidya \& Morris, 1972; Overstreet, Cooper \& Katz, 1978) and in the inseminate volumes (Overstreet, 1970; Morton \& Glover, 1974b). For example, Overstreet (1970) showed for tubal insemination with a constant number of spermatozoa that fertilization was improved by the use of smaller volumes. In the present experiments sperm numbers and inseminate volumes were very similar. Cohen \& McNaughton (1974) employed excessively high numbers $\left(18 \times 10^{6}\right)$ of ejaculated spermatozoa as the unselected component of the mixed inseminates, thereby introducing a numerical bias against this group when compared with others, particularly as they expressed their results in terms of numbers of spermatozoa inseminated per offspring produced. Moreover, only 47 of their does littered out of 200 inseminated. To put these figures in perspective it may be recalled that maximum levels of fertilization have been obtained with $1 \times 10^{6}$ spermatozoa and that $50 \%$ of does littered when inseminated per vaginam with $1-2 \times 10^{5}$ spermatozoa (Wales, Martin \& O'Shea, 1965). With intrauterine insemination of similar numbers of spermatozoa comparable fertilization rates were achieved (B. Fisher \& C. E. Adams, unpublished). Overstreet \& Bedford (1976) inseminated $6-10 \times 10^{6}$ spermatozoa into the uterine horns of rabbits and more than $75 \%$ of the ova were fertilized, irrespective of whether ejaculated or epididymal spermatozoa were employed.

The postulated selection of spermatozoa by the genital tract was not a regular event: thus, in only $20-25 \%$ of the successful inseminations performed by Cohen \& McNaughton (1974) did the 'selected' spermatozoa show a higher fertilizing potency than the ejaculated spermatozoa. Only $16 \%$ of Cohen \& McNaughton's (1974) inseminations resulted in progeny from both the selected and unselected populations of spermatozoa. The proportion was still lower, $10 \%$, if only inseminations with uterine-recovered and ejaculated spermatozoa are considered. Other data (Overstreet \& Katz, 1977) also reveal a low proportion (2/5) of mixed fertilization after tubal insemination, suggesting that one lot of spermatozoa may have been handicapped in some way. In the present work $53 \%$ (uterine insemination) and $85 \%$ (tubal insemination) of the fertilized eggs were recovered in flushings containing eggs fertilized by both sperm populations.

In our study, however, the composition of the compared sperm populations might have been altered by loss or phagocytosis during the $6 \mathrm{~h}$ incubation interval, thus leading to unrepresentative sub-populations of the former groups of 'selected' and 'unselected' spermatozoa. However, a loss of spermatozoa by ascent from the uteri into the oviducts would have taken place in both populations. Moreover, the numbers of spermatozoa migrating into the oviduct are very small during the first $6 \mathrm{~h}$ p.c. (Braden, 1953; Overstreet et al., 1978), and it was presumed that the final ascent of spermatozoa to the site of fertilization takes place in mated rabbits during the periovulation period from a sperm reservoir in the tubal isthmus (Overstreet $e t$ al., 1978), which is largely filled later than $6 \mathrm{~h}$ p.c. A retrograde passage of uterine-inseminated spermatozoa into the cervix and subsequent re-ascent into the uterus - thus infiltrating the 'unselected' population with 'cervix-selected' spermatozoa-cannot be ruled out, but these spermatozoa are not likely to be representative of our unselected population. Furthermore, more 'selected' spermatozoa should have done better than a few, but fertilization rates were almost equally $50 \%$ (Table 2 ).

Bedford \& Chang (1962) mentioned an increased immune response in intrauterineinseminated rabbits. It is questionable, however, whether a local immune stimulus was effective 
and selectively directed against one population of spermatozoa during the $6 \mathrm{~h}$ incubation time involved in our study. Overstreet et al. (1978) suggest that the spermatozoon-leucocyte association may be reversible. Finally, most vaginally deposited spermatozoa were also exposed to leucocytes because they had passed the cervix during the chosen time interval (Braden, 1953; Morton \& Glover, 1974a; Overstreet \& Cooper, 1978; Overstreet et al., 1978). Further immunological aspects of sperm transport and selection are discussed by Cohen \& Tyler (1980). Some of their experimental evidence and conclusions are open to criticism and disagree with the earlier results; for example, the 'positive selected' uterine spermatozoa in Cohen \& McNaughton's (1974) experiments were recovered about $10 \mathrm{~h}$ p.c., at a time when more than $80 \%$ of uterine spermatozoa should be coated with IgG and regarded as 'negatively selected' by Cohen \& Tyler (1980). But the observation of a non-IgG-binding of spermatozoa up to $3 \mathrm{~h}$ p.c. in the uterus and a possible accumulation of these spermatozoa in the oviduct, together with the finding of Overstreet \& Cooper (1978) of a rapid post-coital populating of the oviduct with spermatozoa which might be relevant for fertilization (Overstreet et al., 1978), would lead to a possible model for a selection of spermatozoa on an immunological basis, perhaps depending on timing principles. Such a model could explain the results of Overstreet \& Katz (1977) (see above). It could not be proved, however, in our study because the 'selected' spermatozoa were no longer present in the final mixed inseminates of 'cervix-selected' and 'unselected' spermatozoa.

Contrary to the findings of Pursel, Johnson \& Borkovec (1975) in the pig and Beil et al. (1976) in the rabbit, we found that TEPA-treated spermatozoa, when mixed with untreated spermatozoa, fertilized significantly fewer eggs. However, neither motility nor agglutination, nor the proportion of spermatozoa stained ('live-dead') differed as a result of treatment. The spermatozoa were exposed to TEPA for a similar length of time but we used a slightly higher concentration $(1.3 \mathrm{mg} / \mathrm{ml})$ than did Beil et al. (1976) $(1 \mathrm{mg} / \mathrm{ml})$. R. J. Wall (personal communication) has found that $1.2 \mathrm{mg}$ TEPA $/ \mathrm{ml}$ depressed the fertility of rabbit spermatozoa compared with $0.6 \mathrm{mg} / \mathrm{ml}$; however, the higher concentration was more effective in blocking cleavage.

We are indebted to Dr A. B. Borkevec, USDA, Beltsville, Maryland, U.S.A., for the gift of TEPA; Dr C. Polge and Dr H. M. Dott for their helpful advice; and Ms W. Hutchings and $\mathrm{Mr}$ M. Davis for technical assistance. B.F. was in receipt of a grant from the "Deutscher Akademischer Austauschdienst" (DAAD) Bonn-Bad Godesberg.

\section{References}

Adams, C.E. (1962) Artificial insemination in rodents. In The Semen of Animals and Artificial Insemination, pp. 316-330. Ed. J. P. Maule. Commonwealth Agriculture Bureaux, Farnham Royal.

Amoroso, E.C. \& Parkes, A.S. (1947) Effects on embryonic development of X-irradiation of rabbit spermatozoa in vitro. Proc. $R$. Soc. $B$ 134, 57-79.

Beatty, R.A. (1960) Fertility of mixed semen from different rabbits. J. Reprod. Fert. 1, 52-60.

Bedford, J.M. \& Chang, M.C. (1962) Fertilization of rabbit ova in vitro. Nature, Lond. 193, 898-899.

Bedford, J.M. \& Overstreet, J.W. (1972) A method for objective evaluation of the fertilizing ability of spermatozoa irrespective of genetic character. $J$. Reprod. Fert. 31, 407-414.

Beil, R.E., Bauman, D.A. \& Graves, C.N. (1976) Tepa-A marker for use in evaluating fertilizing ability of rabbit spermatozoa in competitive fertilization. Biol. Reprod. 14, 398-400.

Braden, A.W.H. (1953) Distribution of sperms in the genital tract of the female rabbit after coitus. Aust.J. biol. Sci. 6, 693-705.

Chang, M.C. (1951) Fertilization in relation to the number of spermatozoa in the Fallopian tubes in rabbits. Ann. Ostet. e Ginecol. (Milan) 2, 918-922.

Chang, M.C. (1952) Fertilizability of rabbit ova and the effects of temperature in vitro on their subsequent fertilization and activation in vivo. J. exp. Zool. 121, 351-382.

Chang, M.C., Marston, J.H. \& Hunt, D.M. (1964) Reciprocal fertilization between the domesticated rabbit and snowshoe hare with special reference to insemination of rabbits with an equal number of hare and rabbit spermatozoa. J. exp. Zool. 155, 437-446.

Cohen, J. \& McNaughton, D. (1974) Spermatozoa: the probable selection of a small population by the genital tract of the female rabbit. J. Reprod. Fert. 39, 297-310.

Cohen, J. \& Tyler, K.R. (1980) Sperm populations in the Downloaded from Bioscientifica.com at 04/26/2023 11:47:25AM 
female tract of the rabbit. J. Reprod. Fert. 60 , 213-218.

Dandekar, P., Vaidya, R. \& Morris, J. M. (1972) The effect of coitus on transport of sperm in the rabbit. Fert. Steril. 23, 759-762.

Dott, H.M., Harrison, R.A.P. \& Foster, G.C.A. (1979) The maintenance of motility and the surface properties of epididymal plasma. J. Reprod. Fert. 55, 113-124.

Götze, G. (1973) Die Wirkung von Röntgenbestrahlung, von Samen-konservierungsmethoden und von Ovulationsbeeinflussungen auf die Befruchtung und den embryonalen Fruchttod beim Kaninchen. Dissertation, Tierärztliche Hochschule Hannover.

Mortimer, D. (1977) The survival and transport to the site of fertilization of diploid rabbit spermatozoa. $J$. Reprod. Fert. 51, 99-104.

Morton, D.B. \& Glover, T.D. (1974a) Sperm transport in the female rabbit: the role of the cervix. J. Reprod. Fert. 38, 131-138.

Morton, D.B. \& Glover, T.D.(1974b) Sperm transport in the female rabbit: the effect of inseminate volume and sperm density. J. Reprod. Fert. 38, 139-146.

Overstreet, J.W. (1970) Sperm numbers and fertilization in the rabbit. J. Reprod. Fert. 21, 279-288.

Overstreet, J.W. \& Adams, C.E. (1971) Mechanisms of selective fertilization in the rabbit: sperm transport and viability. J. Reprod. Fert. 26, 219-231.

Overstreet, J.W. \& Bedford, J.M. (1974) Transport, capacitation and fertilizing ability of epididymal spermatozoa. J. exp. Zool. 189, 203-214.

Overstreet, J.W. \& Bedford, J.M. (1976) Embryonic mortality in the rabbit is not increased after fertilization by young epididymal spermatozoa. Biol. Reprod. 15, 54-57.

Overstreet, J.W. \& Cooper, G.W. (1978) Sperm transport in the reproductive tract of the female rabbit. $I$. The rapid transit phase of transport. Biol. Reprod. $19,101-114$.

Overstreet, J.W. \& Katz, D.F. (1977) Sperm transport and selection in the female genital tract. In Development in Mammals, Vol. 2, pp. 31-65. Ed. M. H. Johnson. North Holland, Amsterdam.

Overstreet, J.W., Cooper, G.W. \& Katz, D.F. (1978) Sperm transport in the reproductive tract of the female rabbit. II. The sustained phase of transport. Biol. Reprod. 19, 115-132.

Pursel, V.G., Johnson, L.A. \& Borkovec, A.B. (1975) Effects of in-vitro treatment of boar spermatozoa with TEPA on the fertilization and development of pig eggs. J. Reprod. Fert. 45, 549-552.

Roche, J.F., Dziuk, P.J. \& Lodge, J.R. (1968) Competition between fresh and aged spermatozoa in fertilizing rabbit eggs. J. Reprod. Fert. 16, 155-157.

Wales, R.G., Martin, L. \& O'Shea, T. (1965) Effect of dilution rate and of the number of spermatozoa inseminated on the fertility of rabbits ovulated with chorionic gonadotrophin. J. Reprod. Fert. 10, 69-78.

Received 2 May 1980 